\title{
Intensities of mobility: kinetic energy, commotion, and qualities of supercommuting
}

David Bissell, Phillip Vannini and Ole B. Jensen

\begin{abstract}
This paper explores the intensities of long distance commuting journeys in order to understand how bodily sensibilities become attuned to the regular mobilities which they undertake. More people these days are travelling farther to and from work than ever before, owing to a variety of factors which relate to complex social and geographical dynamics of transport, housing, lifestyle, and employment. Yet, the experiential dimensions of long distance commuting have not received the attention that they deserve within research on mobilities. Drawing from fieldwork conducted in Australia, Canada, and Denmark this paper aims to further develop our collective understanding of the experiential particulars of long distance workers or supercommuters. Rather than focusing on the extensive dimensions of mobilities that are implicated in broad social patterns and trends, our paper turns to the intensive dimensions of this experience for supercommuters by developing an understanding of embodied kinetic energy, commotion and quality. Exploring how experiences of long-distance workers are constituted by a range of different material and bodily forces enables us to more sensitively consider the practical, technical, and affective implications of this increasingly prevalent yet underexplored travel practice.
\end{abstract}

Keywords: Commuting; Body; Travel; Transport; Intensity; Mobilities. 
Recent research on bodily experiences of mobility has, for the most part, tended to cluster around two geographical poles: everyday movements at the local (especially urban) level (Edensor, 2003; 2011; Wilson, 2011; Laurier and Lorimer, 2012; Waitt, Harada and Duffy, 2015), and the cross-border travels of migrants, workers, and tourists at the trans-national level (Burrell, 2011; Conradson and McKay, 2007; Sheller and Urry, 2004). This has resulted in minimizing attention to the experiences of a sizable group of people who are engaged in routine forms of mobility that go beyond the local and urban level, but that are not quite as broad-ranging as international travel. These people are what we may call long-distance commuters or "supercommuters." These are individuals who live far from their place of work and who cover long distances on a regular basis, typically by travelling one or two hours in length, or even longer, multiple times a week. Supercommuters' relative absence from the literature is partly owing to the fact that they are a relatively new phenomenon enabled by fast modes of travel, efficient intermodal connections, and by the spreading of urban populations in farther suburban and exurban environments (see Ralph, 2014; Viry and Kaufmann, 2015).

From an academic perspective, supercommuters' lives plug into a suite of well-trodden concerns about the environmental impacts of transport and urban sprawl, the (im)possibilities for place attachment and community involvement, and an allegedly strained work-life balance (Kelly and Donegan, 2015). Indeed the small body of existing research into this population has tended to focus on the socio-psychological motivations of people involved in these journeys, thus eliciting a host of answers: their lives are a response to the growing availability of advanced technologies of transport; they are expressions of a controversial "lifestyle choice;" and they are a response to rising urban housing costs (Sandow and Westin, 2010; Hardill and Green, 2003). Supercommuters' lives are even often profiled in the news media in a manner that conveys a pervading sense of marvel and disbelief toward their routines, as if this were an extreme life that is clearly unsustainable, a life that is dangerously close to imploding, and a life that is quite simply unimaginable. ${ }^{2}$

Our paper is motivated by empirical and conceptual aims. Empirically, we are interested in providing a more ethnographically detailed and nuanced look into the experiences of supercommuters, in the hope of contributing knowledge to a subject only infrequently examined by mobility researchers. Conceptually, we are motivated by an interest in refining our collective understanding of the idea of intensity. There are three main reasons for concentrating on this concept. First, common representations of long distance commuters suggest that undertaking these journeys and experiencing commute-centred lifestyles is an intense experience. Second, we contend that the concept of intensity is often mentioned but it has not been adequately explored in mobilities research. Third, and more inductively, notions directly or indirectly related to the intensities of travel and of fieldwork kept re-occurring in our respective data sets and thus we felt it necessary to deepen our grasp of it. By gathering these three entry points together, this paper aims to develop a better understanding of the concept of intensity especially as it pertains to the lives and mobility experiences of long distance commuters. Given our interests and data, we are primarily interested in how the concept of intensity spotlights the singular and situated dimensions of mobility experiences that often get sidelined in more generalising socio-psychological explanations for commuting practices.

This paper is the result of a unique three-way collaboration. Driven by a common interest in the experiences and practices of supercommuters, the three of us made a plan to draw upon original empirical data collected at three separate sites with three different types of supercommuters. Research project A focused on supercommuters in Australia. During 2013, Author A conducted

\footnotetext{
${ }^{1}$ There are multiple definitions of supercommuters, according to specific attributes. For example one definition is a one-way journey of over $100 \mathrm{~km}$, see BITRE, 2012. We aim to keep our definition intentionally broad to encompass the gap between shorter urban commutes and longer international journeys.

2 TV examples include the UK Channel 5 series "Britain's Craziest commutes"

http://www.channel5.com/show/britains-craziest-commutes. Print media examples include http://time.com/9912/10-things-your-commute-does-to-your-body/
} 
loosely-structured interviews with 53 commuters in Sydney who responded to a newspaper advert calling for participants who experience stress as part of their everyday mobile life. Participants routinely travelled by a variety of modes of transport and revealed a rich diversity of employment situations and commuting scenarios. The journey time and distance of a significant proportion of respondents was well above the average Sydney commute of 35 minutes each way.

Research project B concentrated on jet supercommuters in Denmark: frequent fliers of a 45 minute daily Scandinavian Airlines flight connecting the cities of Aalborg and Copenhagen. During November and December 2015 the chairman and four members of the Aalborg-Copenhagen Commuter Association, "SKAAL," were interviewed about their experiences ${ }^{3}$. Interviews were openended and semi-structured and focused predominantly on coping with everyday commuting by airplane, the nature of the association, and the skills, experiences, and practices of these experienced "aerocommuters." All the five interviewees are senior employees within management consulting, telecommunication, and HR.

Finally, research project $C$ zeroed in supercommuters in Canada. For this project author $C$ interviewed 18 floatplane pilots working for commercial companies based in coastal British Columbia. Floatplane pilots are unique commuters: unlike other supercommuters their journeys do not unfold as return travel between point $A$ (home) and point $B$ (the workplace), but occur as routine travel between point $A$ (home) and multiple other points throughout the day-with work happening not at point B but rather in between all these points. Interviews with floatplane pilots were open-ended and semi-structured, and were filmed for the purpose of producing a video documentary. ${ }^{4}$

After this introduction we turn to a theoretical discussion of intensity. In that section we discuss the conceptual underpinnings of the idea as it bears on the material and embodied dimensions of supercommuting. This is followed by our empirical section, which contains three sitedistinct empirical impressions, drawn from our respective fieldwork. These "impressions" - written in an impressionistic narrative style to evoke the sensuous, temporal, and place-based intensities of our encounters (see Van Maanen 1984) - are intended to provide the reader with a densely affective and embodied feel of the people and experiences we dealt with. Finally, we engage in analysis and discussion-focusing in particular on intensity as a form of kinetic energy-and a brief conclusion.

\section{Conceptualising intensity: three cuts}

The concept of intensity is often used within mobility research but is rarely elaborated on. For instance, in their overview of the new mobilities turn, Sheller and Urry describe that, in part, this paradigm's novelty comes from "the speed and intensity of various flows [which] are greater than before" $(2006,209$, emphasis added). Here intensity refers to a certain "quality" of flow. Later, they go on to suggest how the new mobilities turn introduces "a more relational approach to the classic problem of agency and structure [and] brings to the fore the movements implicit in identifications, grammars, economies, intensities, and orientations" (2006, 216, emphasis added). In their introduction to the Handbook of Mobilities, Adey and colleagues note that "all this mobility is happening incredibly unevenly, at different paces and intensities, with varying impacts and consequences" (Adey et al. 2014, i, emphasis added). Later on, they ask "what might emerge from these encounters of mobile publics in new configurations and intensities of mobility?" (2014, 14, emphasis added). Yet, neither Sheller and Urry, nor Adey and colleagues expand on this idea. Given the prevalence of this important concept, we contend that it is high time for further exploration. There are three different conceptualisations of intensity that we outline here.

Our first cut is drawn from Meaghan Morris's (1988) classic essay "Intensities of staying at Henry Parkes Motel" which provides a useful starting point for our elaboration. At the time this

\footnotetext{
${ }^{3}$ Thank you to Research Assistant, Elias Melvin Christiansen who conducted the SKAAL interviews.

${ }^{4}$ The documentary, available at https://vimeo.com/158735867 (temporary password: deHav1lland) and the research process are discussed in further detail in (forthcoming identifying reference).
} 
essay was written much debate was happening across the humanities and social sciences about the usefulness of dualistic thinking. Morris responded to these debates by explaining how an apparently ordinary motel in regional New South Wales, Australia, is actually quite extraordinary, owing to complex entanglements that cannot be explained away by the simple dualisms of home or away, and permanence or transience. Morris demonstrates how the Henry Parkes Motel is simultaneously a place of tourism, a home, and a community centre, amongst other things: in short, a place of extraordinary intersecting processes and practices. She describes the motel as "a spectrum divided by degrees of duration, intensities of 'staying' -temporary, intermittent, permanent" $(1988,8)$. What we can take from this is that intensities are about complex, fine-grained qualitative differences that cannot be straight-jacketed into the confines of hard-edged, pre-defined categories. Morris's essay has been influential for mobilities researchers who have taken her idea of differential intensities to other sites that are characterised by tensions of movement and fixity, such as petrol stations (Normark, 2006).

Our second cut prompts us to travel back to the turn of the twentieth century, when migration from rural areas to the growing economic urban powerhouses was leading to new sensory experiences that deeply fascinated the sociologists of the day. In this regard, Georg Simmel's pathbreaking essay "The metropolis and mental life," is an anxious reflection on how new urban environments, arguably made up of new mobilities, were leading to "the intensification of nervous stimulation" $(1969,48)$. Simmel writes about how this intensification was principally due to the "rapid crowding of changing images... and the unexpectedness of onrushing impressions" (ibid) that characterises urban life, contrasting markedly from the slower, more 'habitual' rhythms of rural life. Simmel points out that this intensification uses up more "consciousness," which leads these new urbanites to develop an intellectual strategy that protects the body. He says: "in the blasé attitude the concentration of men and things stimulate the nervous system of the individual to its highest achievement so that it attains its peak. Through the mere quantitative intensification of the same conditioning factors this achievement is transformed into its opposite and appears in the peculiar adjustment of the blasé attitude" $(1969,52)$. In short, intensification of nervous stimulation and the energy that it uses up, creates the need to develop management strategies which de-intensify these stimulations, thus "preserving" the self. This development of strategies to de-intensify stimulation can be traced through other sociological work that has been influential to mobilities research, such as Goffman's (1963) idea of "involvement shields" which work to make individuals "inaccessible" to others, creating a kind of "civil inattention." In this vein, research by Jensen (2006), Jiron (2010), and Bissell (2010), have each drawn on Goffman's work to explore how people on the move develop such strategies.

Our third cut draws on theories of affect. To provide a little context, theories of affect have questioned our commonplace understanding of what a body actually is. Rather than a discrete biological entity, from this perspective, a body is a set of constitutive relations and connections with other bodies. A body is "what it can do, the things it can perform, the linkages it establishes, the transformations and becomings it undergoes, and the machinic connections it forms with other bodies, what it can link with, how it can proliferate its capacities" (Grosz 1994, 165). ${ }^{5}$ Deleuze, one of the key thinkers on affect, understands the body as a "site for the circulation of energetic intensities" (Grosz, 1994, 138). So what does this mean? Through his readings of Bergson and Spinoza, Deleuze says that we have tended to think about qualitative intensities in quantitative terms. In other words, of more or less of a quality-such as temperature or speed-in terms of quantitative differences. However, Deleuze's point is that a measurable, quantifiable understanding of intensity misses the qualitative nature of an intensity in terms of how it produces difference in relation to itself, rather than in relation to a pre-established identity.

\footnotetext{
${ }^{5}$ Such an anti-foundationalist understanding of bodies clearly has significant implications for thinking about mobilities, in terms of questioning the durability and stability of bodies on the move which previous modes of thinking often imply.
} 
From the perspective of theories of affect that draw their inspiration from Deleuze's reading of Spinoza, intensity is the "red thread" that weaves the concepts of affect, feeling, and emotion together. This relationship is neatly summarised by McCormack, who writes: "affect, as a field of prepersonal intensity; feeling as that intensity registered in sensing bodies; and emotion as the sociocultural expression of that felt intensity" (2008, 414 , emphasis added). So what bodies' sense is not intensity as such, but the registration of intensity. As Mader puts it, "although intensities are the source of sensations and of experience, [they] are not sensed or experienced as intensities themselves. It is the coupling of an intensifying or remitting quality with an extension that is the way in which intensities are registered. In other words, they are only registered by their impact as extended qualities, or qualities as extended" $(2014,239)$. So from a Deleuzian perspective, intensities are virtual potentials; whilst extensities are actualities. From this definition we can see that affects are intensities. Seigworth and Gregg (2010,1, emphasis added) concur when they say that:

affect is an impingement or extrusion of a momentary or sometimes more sustained state of relations as well as the passages (and the duration of passage) of forces or intensities. That is, affect is found in those intensities that pass body to body (human, non-human, part-body and otherwise), in those resonances that circulate about, between and sometimes stick to bodies and worlds, and in the very passages or variations between these intensities and resonances themselves.

Whilst being mindful that these three thinkers are concerned with different problematics and through different ontological frames, at this point we want to clarify what we find particularly helpful from these three cuts for mobilities research. From Meghan Morris, we can see how intensity can be understood as a methodological device. It allows us to explore fine-grained qualitative differences in mobile experiences, opening up rich spectrums of differences, rather than the empty shells of pre-given categories. From George Simmel, we can see how intensity can be understood as a quality. It gives us a way of understanding how mobile bodies are in the thrall of different qualities of stimulation and the skills that those bodies develop to cope with those qualities. From Gilles Deleuze, we can see how intensity is a force. It gives us a way of understanding how bodies on the move are transformed by impersonal forces, because to feel an intensity is to have experienced a rupture, a difference of intensity, however minute (Simont, 1999).

Scott Lash helps to clarify for us just what is at stake in the concept of intensity. His argument is that "extensive culture is a culture of the same: a culture of equivalence; while intensive culture is a culture of difference, of inequivalence" $(2010,3)$. His point is that we have entered a new realm of intensive politics that is different from older forms of "extensive" politics that were characterised by hegemony. "Extension is homogeneity and identity, intensity is heterogeneity and difference," Lash observes $(2010,4)$. This has important implications for how we approach the question of fieldwork and the presentation of our research. Lash says that that to engage intensively is about engaging with things in terms of their singularity, rather than engaging in terms of a generality $(2010,12-13)$. In large part this is why we have focused our writing below on specific situations where, through our embodied encounters with people and things, we have attempted to draw out their singularity. From this discussion of the conceptual background we move now towards a specific focus on the embodiment and the physical and kinetic dimensions of three different events. After our three impressions we build on the concept of intensity through the ideas of kinetic energy, commotion and quality.

\section{Presenting impressions of intensity}

Oceanic Encounter

"Do you know about this place?" Jack asks me cagily, the way someone does when trying to get a shorthand sense of someone else's worldly horizon. "No," I respond, as he pushes the white-framed glass-panelled door. He turns to me. "Is this OK?" he asks. Another test possibly. "Yeah, of course," I 
say, perhaps a fraction too late. This is the Oceanic Cafe, as the neon green sign outside announces. I have often stood outside this place, waiting for a bus at the tired end of the day. Sometimes my eyes catch the white, roughly-written capital letters on the window: "Today's special: Beef Rissoles"; "Special: Lamb's Fry." On entering, the reek of frying fats displace the mixture of hot fumes, hot sweat and hot urine outside. Braids of urine streak the pavement, some more recent than others. Riding over the top of this reek is a slight earthy mustiness that seems to betray this parched city, scorched by the late summer sun. We take a seat in one of the white overpainted, pew-like wooden booths that line the narrow room.

Before meeting, Jack indicated that he is a long-distance commuter, travelling over $100 \mathrm{~km}$ each way to work every weekday for the last 13 years. The flat coordinates that I came to this interview encounter with told me that he gets a train from the Blue Mountains to the city, and then a bus to his place of work south of the city centre. Yet such coordinates mask the intensities that are to bead the interview.

After ordering a cup of tea, I ask Jack about his journey into Sydney today. "I take the seat I prefer: third carriage, upstairs, on the right. Quite sunny; and then look out the window: beautiful clouds down in the valley. You know, I look at everything." He interrupts himself: "If you want to hear this now?" as if about to say something that cannot be repressed any longer. He continues: "so the way I feel about it is: in the morning, you go for a walk through your garden and you look at everything and see what's growing and what's withering and so on; this is like a 110-kilometre walk through my garden." I smile, struck by the beauty of this sentiment. "So I look at everything - what's growing, what's dying; how much water's in the creeks after all that rain on the weekend; who's building stuff, who's demolishing, that kind of thing. And, because I've been doing it for so long, one thing is I kind of know where to look for all the specific things that I do know that I'm interested in. But the other thing is you've sort of got to keep your eyes loose to find stuff that you've never noticed before otherwise, you get locked into, 'Oh, I'm looking there.' But you don't want to get too locked into that, because you want to be able to flow off and notice something-a house or a tree or whatever it is - that you haven't picked before; otherwise you might miss something."

Jack once lived in Sydney. "I'd never really lived west of Newtown," he admits. "I'm an old Darlinghurst boy from the seventies. So really, I know the name of every street and lane here and I know everything that's gone on here since the seventies-know it really well," drawing out the last two words as if to emphasise this truth. A staging post between his bus and train journeys now, it turns out that the Oceanic Cafe is a place that folds Jack's past life in Sydney with his present commuting life in the mountains. This place also knows everything that has gone on here. Its décor has changed little over eight decades. Along both sides of the café is a row of coat hooks that would have once held gentlemen's hats. Jack tells me that the older lady sat slumped in the chair at the back has worked here since the 1930s. You still get two slices of dazzling white Tip Top bread with every meal.

Jack says that he moved to the Blue Mountains in the hope of finding work there, but to no avail. "When I started doing the commute, I thought, 'I've made a terrible mistake; I can't keep doing this,"' he says. "But like all things you get used to it after a while. But I wasn't that good at it at first." I ask him how so? "That prickly sweat of anger-either at someone on the train, an individual, or the railway system generally. Nowadays, I mean, I really have thought for quite some time, if the train doesn't crash and we're not killed, we're doing really well." Philosophically, Jack says, "after going through every kind of possible situation-I'm much, much more patient than I ever was, you know." Although such patience feels tensed when he reveals that he carries an umbrella at all times for selfprotection on the train. My stomach tenses as when I suddenly realise that a large, tightly folded steel-tipped brolly is propped up against the blue-green Laminex tabletop. Rain isn't forecast today.

Jack has done captioning work for television companies for many years. "It was quite a good job in those days, you know: respect and pay. The respect has gone and the pay has stayed the same," he says, dourly. That his job could get taken away by automation technologies any day now adds to my sense of the precariousness of his situation. As some consolation, I ask whether the real- 
time nature of the job means that he can leave work without bringing it home. "It pesters me all the time," he says, to my surprise. "I should be able to do that because it's largely kind of factory work what I do; we're manufacturing captions," he says. "No, no; I'll sit up writing vicious emails or brooding about the bad behaviour. You know, pathetic playground bullies and pinhead management morons." He says that they offered him home-work, presuming that his commute was tough. He suspects that it's a plot to remove him from the workplace. "They'd say, 'Oh, such a great benefit of working from home.' Well, sorry; I would lose all my great time for myself on the train, which actually I do enjoy to a great degree."

Jack tells me that this commute is like crossing a threshold between different countries. "You're a thousand meters above sea level; the air is different to the air down here," he says. "So you know that on a cold morning, minus five, minus six, which Sydney never gets. So, you know, it's different country." He tells me that he could name every station all the way. Even at night he would be able to tell exactly where he was, such is the familiarity of his route. He delights in telling me about the history of his route. "Just to see all the people write off the western suburbs as if it's just all one amorphous thing and that it's some horrible barren desert; but it's not," he says. "This is a railway track that's well over 150 years old. And so this is, like, the intensive built-up part of the western suburbs. So much of it is paddocks and bushland and parks and creeks. You know, it's a living, breathing place." He senses the other journeys that intersect his commute: "Everything from south to north has to cross at certain points. At Leura, if you stand on the station, spring or autumn, in these couple of weeks, you will see endless thousands of honey eaters, all the different kinds, because they travel south and north because of the change in season. They will come over in a big wave and, it's because they all want to be together; they don't want to be alone. If you live up on the ridges there, you'll see that in its season."

In spite of his reflections on how the job pesters him, I sense that Jack values his free time once he arrives home. "The winding down, you know: it's not that I'm really wound up but, you know, I'm wide awake. I mean, even if I was asleep on the train and I'm very tired, I've got the stimulating walk from the station back home, which is only 10 minutes but you're walking, you're breathing mountain air and you're seeing a lot of stars if it's a clear night." Where others told me that their free time is curtailed, he says "You've still got to have some life; you know what I mean? I mean-otherwise, when are you going to do all the drinking and smoking?" I grin, noticing his slightly yellowed fingertips. "So, when you get home, open a bottle of wine, have a few ciggies, everything's okay. And, I mean, it's not extravagant, and you're bloody tired", he adds, as if to justify this point. "I'm an old rock-and-roller," Jack admits. "Whether I've been unemployed, bone idle or working in a job where I'm meant to be there at eight o'clock in the morning-I've spent my life staying up till three o'clock in the morning." He says that to wake up at 5.30 in the morning means that he has to force himself to be in bed by 1.30 "because, you know, you can't really get by with less than that".

Whilst I feel mildly nauseous at the idea of four-hour sleep, Jack says that his body has become used to his routine. "I' $m$ one of those people that wakes up a couple of minutes before the alarm goes off," he says. "You know, I'm a terribly lazy person," he says. "I hate getting out of bed in the morning. But, when it comes to the train, I like to be there." This bodily anticipation is almost too habitual as he recounts a moment where he woke up late and phoned work to say that he'd be in late. "And young Joe said, 'Jack, it's Saturday."' At this moment his recollections go back further still. "I did that once in primary school. I jumped up, put on the school uniform, ran out the door and caught the bus, you know, thinking, 'This is very odd, ' you know!"

Reminiscent of the French idiom metro-boulot-dodo, Jack says "I am like everyone elsecaught in a vicious cycle of: you've got to go to work to get the money to be able to live to be able to go to work." But then he changes his tone. "No one's that trapped that they can't get out." Whilst he concedes that some people are forcibly trapped, he says "the world's full of migrating human beings and it always has been since people started; they just move." He adds "If it's that bad, do something about it, I would say; although, I mean, you know-I don't know," as if a thousand tensions had 
suddenly seized this remark. Reflecting on his own work circumstances, he says "I've had really crap, badly paid jobs where you think, 'If I quit this job-well, I can't, because we'll get evicted from the flat in a week,' and, you know, that's a disaster. But you've got to have a dream somewhere that this isn't permanent, you know? And, of course, nothing is that permanent; nothing's permanent," arcing back to his earlier reflections on the building and demolition that take place along his commuting route. Thinking back to Jack's descriptions of his current work, his reflections seem to accrue greater poignancy. "I've had this job for a long, long time-for me. But, before that, l'd had a million other jobs, you know, or hundreds-hundreds, you know. Some last a day, some last a year or more."

I've drunk my tea and Jack has finished his dinner. Our crockery has been cleared away by the owner's daughter. Since we arrived, a few other people have come in: mostly lone diners as if reenacting an Edward Hopper canvas, looking like they've done this before. We pay and leave, the sun now hanging low over the roof of the railway station opposite. I shake Jack's hand. He waits at the crossing to resume his commute back to the mountains. As I turn and walk towards my bus stop, I'm struck by how Jack's recollections defy any easy narrative about long distance commuters. His reflections on his changing tendencies in the thirteen years that he has been doing this attest to joys, resentments, frustrations, and tiredness: a dazzling spectrum of often ambiguous and indeterminate intensities that were heightened by detours into different past lives, and spectral futures. I glance back one more to the café, happy that its neon green sign will likely always evoke my strange encounter with Jack.

\section{Aerocommuters institutionalized}

"No, I can't park there!" I am running late for a routine work trip from Aalborg to Copenhagen. The trip is a 30-40 minutes direct flight (or $224.61 \mathrm{~km}$ as the crow flies) - not bad in comparison to a $4 \frac{1}{2}$ hour car drive or a 5 hour train trip. I am scheduled for the 10.30am departure and that -as it always goes with these late morning flights-means a hard time finding a parking space (why is it that parking spaces seem to either fill up mysteriously in the middle of the night, or have all been taken over by tourists who are enjoying the sun in exotic places while I am struggling to find a space to dump my car?). "There is a spot over there but I can't take it," I mumble as I pass the dedicated commuter parking area: a result of the Aalborg-Copenhagen Commuter Association's negotiations with the Aalborg airport managers. The commuting association, SKAAL, has since 1999 coalesced the regular airplane commuters travelling between Aalborg, in the Northern periphery of Denmark, and Copenhagen.

SKAAL has approximately 150 members and has two chief purposes. The first is to work as political voice on behalf of the commuters. The association collaborates with airline companies and regularly puts pressure on travel authorities and airports, and is, as such, an authentic lobby. For example, as of late SKAAL has been very critical of a new re-arrangement of domestic air traffic in Copenhagen airport which has resulted in adding time for security checks. In addition to lobbying the association organizes social events and gatherings for its members: its second raison d'être. Its name gives its jovial identity. SK is the airline code for Scandinavian Airlines-which used to be the sole operator of this route (now Norwegian is operating an equal number of daily flights)-and AAL is the airport code for Aalborg. Put together the letters form the word "skaal" which is Danish for "cheers"! They throw a decent Christmas party too, I am told.

Dedicated parking space was a significant concession. The Chair of the board of, a senior female Management Consultant, explains the victory like this: "In Aalborg Airport we have made an agreement with the airport management that we are given 80 direct parking spaces. This means we can park very close to the airport terminal [...] so I have ten steps from my car to the terminal and ten steps on the other side to pass through fast track." I too wish I had only ten steps to make. I have finally a parking space, ad as always I have to do a large amount of walking from the far corner of the airport parking lot. As I walk against the almost always present strong western wind towards the terminal building, I realize that I should have left the office a bit earlier. Whenever I am on the mid- 
morning flight I tend to first pass by the department to fix a few things. This, it seems, turns out to be a bit of a bad habit.

Once in the terminal building I hurry for the security check and do my usual routine of collecting all my loose objects (wallet, keys, Phone etc.) in my jacket so that it all come off nice and easy when I get ready for security inspection. Despite this I find myself overtaken by the commuters in the fast track check-in line: another example of the smooth running mobility politics performed by SKAAL. Finally I make it the departure gate once again without missing my flight. In fact I never do, but this complex aeromobility system creates certain over-cautious behaviors amongst the more control-minded of us passengers. I check my e-mails on my phone as do the rest of my flying mates this morning. I nod and say hello to a couple of colleagues from another department in the University. We catch these flights to Copenhagen often, but even the busiest of us don't qualify to join the everyday supercommuter SKAAL club. "Well, all the same," I think as I grab a cup for the ritual coffee served on this short haul and join the line of passengers ready to walk across the tarmac. The 737 is waiting to welcome us, our bags, and the work personnel.

I usually check-in online well before a trip, mostly in order to secure an aisle seat-which for some odd reason I have come to regard as the only interesting seat in an aircraft. This notion, however, I have found through the interviews is shared by the supercommuters. So, who knows? Perhaps this attachment for aisle seats is indication of my slow transformation into an experienced air traveler!

We are now at cruising altitude when suddenly a rough outburst of turbulence not only sidetracks my thoughts but also brings my half-full coffee cup dangerously close to the edge of my tray. Quickly restoring local order and compensating the disorder of gravity I see a businessman calmly talking to a female passenger that looks less than relaxed. Interview data have taught me that this is not unusual. SKAAL members often take on a special role as in-flight mediators, calming down anxious fellow passengers with less experience than them. There is an interesting collaborative bond between the aerocommuters and the aircraft personnel as they-just like the flight attendants-are recognized to have particular skills and competencies. One interviewee explains it like this:

"Commuters give a sense of security to the other passengers, they are able to verbalize things, and bring calmness and respect. [The commuter] simply becomes part of the routine." The commuter in fact becomes part of the aeromobilities assemblage so the airline company may rely on the tacit collaboration between these "special passengers" and the cabin personnel in situations of stress. SAS even once invited-another interviewee revealed-the commuter association to visit the SAS Academy in Sweden and taught them about emergency procedures. Clearly, the airline recognizes the supercommuters' level of skills for coping, skills developed over time as an important resource. In virtue of this supercommuters are enrolled as bona fide "mobility helpers" through their tacit understanding of the occasionally frightening flying conditions.

From my general experience with flying I know that there are differences in skills and coping abilities amongst passengers. Who has not seen an elderly couple carrying a bunch of bags looking rather lost in the gangways of the air world? But even for a regular and experienced passenger like me, I too have to recognize that the supercommuters are much farther ahead in their adaptability to the fluxes of the air world. One way to see this is look at the way they tend to make the most of any given situation where a quick nap and a rest is a remote option. In the excerpted words of one supercommuter: "The pattern that exist for passengers who fly a lot is that we embark, we chat and socialize, 'hello, how are you' and 'I am alright' and then we find our seats and as soon as there is push back everyone turns silent. [...] Sometimes there is a novice who keeps talking. If that's the case, you can see the commuters turn and look as if to say 'now it's sleeping time.' Then it's power nap time. You can see it very clearly. Until just before touch down. There are many who wake up just two seconds before we touch the runway. Do you know why? If you are asleep when the wheels touch down you will get a minor shock due to the impact. But you can sense the air pressure. Personally I always wake up 5-10 meters above the ground." 
This impressive skill clearly speaks to the embodiment and multi-sensorial engagement that the high-flyers develop as they intensively inhabit the sky. Supercommuters also work with small practices, tips, and tricks to accommodate the enrolment into frequent aeromobilities. In the words of one interviewee: "I have started to become more alert to my blood circulation. I am not getting any younger, so I am working my feet a bit and move a little, even though it is only a half hour flight, I do fly a lot. SAS has a website where you can see how much you have been flying since January 1 2003 and I have circled the globe 22 times with SAS alone as commuter!" I know exactly just what this commuter means, as I struggle to fit my feet on each side of my computer bag that I didn't manage to store in the overhead compartment before seating down (yes, I missed the aisle seat today; you can't win them all!). Many of the multi-sensorial engagements connected with frequent flying are deeply habitual and highly routinized for these supercommuters. Nevertheless, they also develop a deeper sensitivity to the way the machine interacts with the environment and the outer world as it is clear from their ability to awaken precisely right before the plane touches down on the tarmac. But there are more changes in their awareness. An interviewee speaks about his 'machinic awareness' and sensitivity this way: "I am starting to react to unknown sounds. I am thinking 'what was that?' I can hear if a hydraulic pump doesn't run steady. I don't know why, but it's like if you have a car, there you can also hear if there is an unfamiliar sound, right? I don't know if this is simply routine or if it is some sort of pre-stage for an anxiety, but I can sense that I have started to detect sounds that are unfamiliar." The intensive commute may come with a cost that has not yet been recognized as in the form of a growing anxiety and perhaps even emerging flying fatigue.

As we touch down in Copenhagen I notice that I am not the only one already accessing email accounts and text messages on my smart phone. The taxiing-in from the runway to the terminal is a space of rather intense communication as you hear people giving accounts of delays or renegotiating agreements over the phone. After disembarking the aircraft $\mathrm{I}$, and a substantial number of my fellow passengers, briskly walk towards the Metro station to embark on this almost seamless train connection that in $\mathbf{2 0}$ minutes will take us to the heart of the city. Reminiscent of the old days before the Metro, when all the commuters would run for taxis, I realize that this is one success story of a well-functioning interface between the private sector air-world and the public urban transit system. As I watch my former fellow flights passengers return to their phone screens I ponder about the way in which humans are very adaptable to their environments. It may be me just being philosophical, but we are in fact in a fully manufactured and artificial environment, and nevertheless when I look at my co-passengers they all seem to adapt and act as if this was their most natural habitat in the world, and in a way I guess it is. What for some is considered deeply exotic, is mundane everyday grayness to others. Or as one of our interviewees put it: "to me this [the airplane] is a bus with wings," and I guess it just about is.

\section{Low and slow}

"Well, it's as close to a stable, regular bus-driving job as you can get here," Harold tells me with a smirk, "I call it 'city flying' now. It's not really bush-flying anymore." Harold is chief pilot for Saltspring Air, a small but successful floatplane operator connecting Saltspring Island and Vancouver Island's Maple Bay with downtown Vancouver and Vancouver International Airport. Though he has done his fair share of more adventurous "bush flying" over the years, now Harold is content to wear a casual button shirt featuring his company logo and go "back and forth on scheduled routes four to six times a day" for about twenty days a month in spring and summer, and sixteen in autumn and winter. Despite the routine, Harold calls his job his passion. "It always changes," he says.

The etymology of the verb "to commute" can be traced back to the Latin commütāre, which means to change, exchange, and replace. Though professional operators of collective means of transport are not normally considered commuters, like all other commuters they are involved in rhythmically alternating sites of departure and arrival and therefore in "re-placing" their quotidian spaces in a repeated and predictable manner. Among these operators are floatplane pilots: drivers of transport technologies that may be uncommon in most of the world, but are undoubtedly 
ordinary in places under-served by roads and bridges - places like coastal British Columbia. In order to avoid time-consuming and often costly ferry boat travel to and from the densely-populated lower mainland to Vancouver Island, the Gulf Islands, the Sunshine Coast, the Central and North Coast, and Haida Gwaii, thousands of passengers fly seaplanes daily for work, health, education, and leisure. In addition to scheduled flights floatplanes also regularly fly chartered trips to remote logging camps, fishing lodges, First Nation communities, scientific research sites, trailheads, and countless other places where water access is the only option. Pilots are the unique commuters that make it all happen daily.

Unlike glorified jet pilots floatplane pilots take virtually no part in the extensive relations of global mobilities. Tonight Harold won't be in Bali or Amsterdam, and even though he will have flown almost all day he will never be farther than $25 \mathrm{~km}$ from home. The differences between the two occupations do not end there. "It's not necessarily floats per se," Harold tells me as he slouches on the happenstance lawn chair I've placed for him on the floating dock of the Maple Bay Marina Gas Bar, "I just love the actual flying. You're not flying when you get into the jets. It's more data entry. It's almost like you're not really flying anymore. It's system management, data input, it's a videogame. This is real flying. Here you are making the decisions." This is intense.

Floatplanes are different from jets (on the difference between floatplanes and jets see Jensen \& Vannini, 2016). The most common aircrafts flying in the region--the DeHavilland Beaver and Otter, the Cessna 180, 185, and Caravan-are all characterized by the all-important STOL feature: Short Take-Off and Landing. Unlike jets-which require long, paved strips-STOL airplanes on pontoons can land and depart from small bodies of water. They are highly maneuverable, fuelefficient, and light. Able to carry cargo and/or passengers these planes can carry as few as 4 people (the smaller Cessna's) and as many as 16 (the Otter and Caravan). Not only are they lighter and smaller than jets, but floatplanes also have a much more limited flight range-typically operating 2045 minute trips in coastal BC. Floatplanes are also much slower than jets: typically cruising at about $140 \mathrm{mph}$ at around 1,000 feet of altitude. Because they fly so low and directly into the weather and the landscape floatplane pilots must see where they are going at all times. Thus instead of IFR (Instrument Flight Rules) floatplane operators must abide by VFR: Visual Flight Rules that specify minimum visibility parameters and deeply shape the intensities of flying.

Floatplane pilots all over the coast have been telling me that flying jets is like science. Flying floatplanes, instead they say, is like art. "Yeah it's a good analogy," Harold comments, "With jets, it's instrument flying. When you're flying IFR it's very exact. Every step of that flight is taken care of from the time you get to the airport and you're planning a route. You're getting your weather and dispatch gives you a sheet that says this is where you're going. You program it into the plane and there's no room for winging it. You can't deviate from your set rules." Harold's typical routes take him into downtown Vancouver and YVR - the two busiest airspaces in the region-and therefore he needs to communicate regularly with air traffic controllers. Yet, he explains, he needs to fly his plane with his eyes, not his controllers, his manuals, or his gauges. When you fly VFR, he tells me, "the challenge is the weather. It's always different. I come into Maple Bay and Ganges [Saltspring Island] five times a day, ten times a day, and each landing can be different. If the winds are coming your way you gotta judge if you're gonna land crosswind. If the winds are going the wrong direction you can decide if you're going to land sideways, parallel to swells, if the swells are too big. I mean, each landing you're making decisions five miles away. Ten miles away you're thinking about what my landing is gonna be like this time."

The lazy part of the day is over for both of us. There is no one working here today at Maple Bay "airport" so Harold needs to make a roll call of his passengers, direct them to his turbo Beaver, load their luggage, and brief them on safety. It's all routine for him. The reality is different from me. Though I am intimately familiar with floatplane flying, conducting an on-camera interview in the Beaver's tiny cockpit is a new challenge. Nervously, I connect my camera with my ound recorder, then attach a lav mic to it. Subsequently, I grab the mic and place it in between my left ear and the intercom headset that Harold hands me. Finally I screw in a viewfinder to the LCD screen of my 
camera and buckle my seat belt. As the plane takes off I look like a sorry tangle of wires, cables, and straps.

"Beaver Fox Alpha Oscar Papa. We're in AOP. I gotta call the tower at Pacific Radio now in Kamloops, we got a VFR code to get to Vancouver here so... Pacific Radio this is Beaver Foxtrot Alpha Oscar Papa. Good afternoon." "Yeah, you picked a great day for this," Harold finally says to me after he stops spitting codes. He recounts how yesterday the weather suddenly turned bad and he and many other pilots became stranded on the mainland, unable to fly back home until this morning. "Yeah that's our biggest nemesis," Harold says, "visibility really. And wind. But you know what? Wind we can manage. And you know you can see it. You can see where you're going in the wind. It's funny that passengers, though, they're more concerned with wind than they are with fog, drizzle, bad weather, flying low it seems. They get scared out here and I can understand they're not in control and you get bashed around." I've been in a few of those flights. Fortunately there is little wind today and the sky is turning blue after a few faint morning clouds have faded away. However, I worry about the route. Crossing over the warm landmasses of Saltspring Island first and Richmond later will mean experiencing turbulence due to the differences in warmth convection between see and land. Bumpy flights make for useless footage.

"Alright I gotta switch now," Harold announces, "there's an Otter heading to Vancouver or Victoria probably. Vancouver? Good afternoon." As he learns more, it turns out it is not a Beaver but a helicopter flying somewhere around us. I spot it below us, to the starboard side of our plane, and alert Harold. It's not just the odd chopper and the regular heavy iron flying in from all directions that he has to deal with, Harold tells me. "This time of year from about October to February, you can almost set your calendar to it, there will be thousands of snow geese that show up at the river mouth here. They migrate down from the north. And they'll stay here for about four months." I wonder how a floating Beaver would fare in a wing fight with Snow Geese, but there is no time to ask about animal encounters. "We have a westerly wind, and of course with wind direction we always have to land and take off into the wind. So I'm gonna join downwind as I go along the river. The river and the airport will be on my left and then I go turn around and land westbound over there."

Harold's descriptiveness is not only informative and re-assuring, but also a terrific commentary track for the video I am shooting. To give him a momentary break from the attention I turn the camera away from him, to my right. But he picks up on what my lens is focusing on and comments: "I swear if they build any more high-rises around here we're gonna have some issues." We have a good laugh together as the Beaver dodges vertical development and makes a sharp downward turn to its left, away from Richmond's newest skyscrapers. Harold resumes: "The calmer water is on the very far shore here. So we try and get to the calmest spot we can. Sometimes if it's blowing thirty knots it's not landable in the middle. This is not bad. Still bigger waves though. We'll try and stay over on the side."

Seconds later, we are floating.

"That was a greaser, Harold."

"Thank you, yeah. It was. Well, it's pretty easy on the nice days, we always say."

\section{Materializing Intensities}

Regardless of the sites, conditions, technologies, and actors involved in what we described above, we can think of commuting as the routine and repetitive transition from place to place: a transition ideally meant to be safe, time and resource-efficient, and as comfortable and convenient as possible. But it is in the specific entanglements of that ambulatory transition between places that different intensities of commuter involvement lie. Places - and we can indeed think of both the means of transport as well as the destinations connected by a commute as different types of place-are relational achievements. As Ingold $(2000,186)$ has noted places arise out of the currents of involved activities, out of the precise manners in which the inhabitants of a place are engaged with their surroundings. In this sense we can think of commuting and supercommuting as taskscapes (Ingold 
2000, 2010): differently intense entanglements of various tasks and goals, different circumstances and conditions, variable resources and tools available, as well as many skills, knowledges, and practical orientations. It is by presenting and examining the felt intensities of different supercommuting taskscapes that we can learn a lot about commuting and ordinary mobilities as well in general.

Though train-riding, airplane-flying and floatplane-piloting are all taskscapes, the precise manners of bodily engagement of commuters with their specific surroundings are quite different in both quality and degree of personal involvement from case to case. Riding trains or planes to work requires knowledge of place, timetables, fares, and check-in procedures for example, whereas piloting floatplanes requires attuning to the relations between the affordances of one's aircraft, the configuration of the land- and sea-scape that one is flying in, and the constantly changing atmospheric conditions in which one is suspended. Bodily involvement is necessary in all these cases, but it differs qualitatively across situations. Like a mariner wayfaring the seas through his/her involvement the supercommuter "watches, listens, and feels as he [sic] goes, his entire being alert to the countless cues that, at every moment, prompt the slightest adjustments to his bearing" (Ingold $2007,78)$. The supercommuting body is deeply entangled with the tools under use, the explicit and implicit rules of travel, and the variable goals and changing conditions of a commute, and this entanglement is deeply shaped by the precise uses and functions the transport tool affords (see Vergunst 2011). But at the same time the supercommuting body is always differentially entangled and involved.

\section{Kinetic energy}

In order to understand the nature of such differential bodily involvement within a taskscape we turn to the post-foundational and post-dualistic reading of physics inspired by the three thinkers we have surveyed earlier. At this point, we want to introduce a new concept, that of kinetic energy. In physics the concept of kinetic energy refers to the potential and actual capacities for activity that an object possesses owing to its motion. Kinetic energy is the work that is needed to accelerate a body, or more broadly to put a body into a motion. Kinetic energy is highly variable in relative terms. For instance, it requires a different kinetic energy to move a bicycle uphill than downhill, or against the wind than under windless conditions.

To understand the different qualitative and quantitative dimensions of kinetic energy we tie that idea to the concept of intensity. The idea of intensity lends itself well to qualify types and expressions of kinetic energy. Intensity refers to the degree and extent to which something is acute, strong, frequent, or vehement. So, in our case we can think of kinetic intensity as the variable manifestation of involvement in a taskscape which is required to generate kinetic energy. Understanding kinetic intensity can help us describe and gauge the variable expressions of energy required to be mobile in light of changing social and material conditions and scopes of travel, technological modes of locomotion, and variable relations with one's environmental surroundings.

Over the years mobility researchers have highlighted the different intensities of involvement required by bodies immersed in certain modes of travel. Take for example the variable intensities of motorbike driving (Pinch and Reimer 2012) and bike-riding (Jungnickel and Aldred 2012) when compared to car-driving. Kinetic intensities are not just variable across modes of transportation, however, as they may be quite different from situation to situation even when the mode of transportation is constant. Thus for instance how Spinney (2006), Brown (2012), Fincham (2007), and Jones (2012) have all shed light on the different physical intensities demanded by certain kinds of bike travel characterized by different styles, different tools, and different travel motives and conditions-each with their own differing energies at stake.

We can make a very similar argument for supercommuting. Supercommuting occurs alongside shifting currents of movement and within the domain of complex entanglements of time, space, skill, and many other elements. So involvement in supercommuting arises from having to constantly negotiate risk, accidents, fatigue, stress, anxiety, and discomfort with the variable 
atmospheres and surfaces travelled through, as well as having to continuously assess and monitor conditions, and having to repeatedly anticipate, decide, act, and react to those changing travel dynamics. This of course goes for train commuters, floatplane pilots, and jet passengers alike whoin their different ways - manifest their own special skills, exercise deep sensitivity to the complexities of their transport modes, and manage their bodily responses to fatigue, tension, stress, and perturbation. As is the case for the motel described by Morris (1988), the sites of supercommuting we have described are places of seemingly ordinary but actually quite extraordinary intersecting processes and practices shaped by variable intensities of stasis and movement.

\section{Conditions and commotions}

As indicated by the more Deleuzian take on intensity earlier, our bodies are not sealed off from the outside but rather open to and immersed in the conditions of their existence. For supercommuters the intensity of their involvement in their respective taskscapes therefore varies by type of travel mode and in light of changing material and atmospheric conditions. Darkness vs. light, hot vs. cold temperatures, crowdedness and traffic vs. solitude, friction-less vs. friction-full travel are all variable environmental conditions that envelop the supercommuter's body into a changing travel taskscape, enfolding the commuting body into changing conditions and the need to utilize different techniques, different tools, and different habits and routines to respond to such conditions. A supercommuter's body is thus to be understood in terms of what it can do to be differentially affected by her/his travel and the machinic connections it can form with other human and non-human bodies as it moves and establishes links along the way (see Grosz 1994, 165). So, as the commuter's body changes rhythms and speeds and shifts into higher or lower intensities of effort as the situation demands, differing degrees and types of kinetic energy intersect with variable intensities of qualities of light, of weather, shifting individual and collective moods, and changing ambiances and affective atmospheres-which together contribute to the evolving qualities of a journey (see Cook and Edensor 2014) which are situated and singular.

The supercommuter is an animated subject enlivened by changing "levels" of atmospheric conditions (Lingis 1998) and energized by the need to adjust not so much continuously-as so much of commuting can actually be routine and habitual-but rather instantaneously, at a moment's notice in an expert manner. Exerting kinetic energy is therefore a process of attuning to altered conditions: from an unexpected meteorological event to a broken-down engine, from a sudden workers' strike that freezes traffic to an unexpected delay that forces a re-assessment of a changeover and a new itinerary. In short, kinetic intensities unfold in parallel with the appearance of obstacles, the emergence of ruptures, the manifestation of turbulences, and the formation of frictions. Kinetic intensities fluctuate together with shifting material relations and changing fields of movement.

Kinetic intensities also depend on the socialities of travel and the comingling of commuting bodies: the localized unfolding of shared emotions, feelings, sensations, and affects experienced by the commuting traveller and those around him/her. In this sense, kinetic energy is not a mechanic, cognitive response to changing stimuli. Rather, kinetic intensities are deeply-situated relations oriented to the world in flux-heterogeneous unfoldings, not extensive structures of sameness (see Lash 2010). Intensities depend on the body's kinesthetic awareness of itself, on its affective "gearing" (see Merleau-Ponty 1968) to the evolving tasks and scopes of movement. Sheller (2004) for example writes of "automotive emotions" in relation to the embodied dispositions of car users and the visceral feelings that are associated with driving. "Human bodies," she observes $(2004,228)$, "physically respond to the thrum of an engine, the gentle glide through a gearbox, or the whoosh of effortless acceleration, and in some cases the driver becomes 'one' with the car." Our impressions show how this occurs in quite similar ways to our supercommuters.

But it is not only with the car, with the train, or with the airplane that the traveller becomes one. We can think of kinetic intensities, broadly, as the commotions arising from specific social 
relations demanding the utilization of kinetic energy through which supercommuters affect others and are affected by them (see Massumi 2002; Seigworth and Gregg 2010). Commotion is tumultuous motion and agitation, it is vibrant and alert action. But it is also a type of emotionally touching and affecting, and a type of moving-with and being moved-with others-both non-humans and humans. Kinetic intensities in this sense are susceptibilities, sensitivities, capacities of being liable to shifting affects, moods, and feelings (see Grosz 1994 on Deleuze's thought). To super-commute is thus to super-commove: to be highly responsive to others-both the technologies and fellow travellerswith which and with whom one is moving. From moments of stress and anxiety, to moments of shared frustration and concern, from atmospheres of collective preoccupation to shared sensations of relaxation and comfort, to super-commute is to enact the deeply-attuned capacity to be affected by shifting intensities of collective kinetic energies and to affect them in turn.

\section{Qualities}

Kinetic intensities are dynamic interplays among shifting assemblages that create singular qualities which are registered by sensing bodies. To explain what we mean by this, we turn to Massumi's reading of CS Peirce. He asks "Could anything be more intense than the presence of a quality 'just as it is, regardless of past and future, utterly ignoring anything else', in absolute immediacy"? (2016, 120). Massumi here is anxious of the analytical impulse of traditional empirics where the tendency is to decompose qualities into component parts: the quantitative intensities of pressure, light, temperature, for instance. But this is not quality, because quality is not an object. Quality 'is qualitative immediacy at its intensest' $(2016,121)$. To illustrate this point, he provides us with a helpfully mobile example. "Qualities have intensity, not scale" he says, "This means that an immediate presentness of Quality may make itself felt in situations we would normally think of... to be large-scale and composed of many sub-units. Like stepping off a train into the bustle of Central Station at five o'clock on a winter Monday morning. There is a quality of feeling to that. There is a different quality to five o'clock in the afternoon" $(2016,123)$.

To return to our vignettes in this light, what they enact are the singular intensities that rise and fall through our fieldwork encounters themselves. Our aim has therefore not been to analyse our three vignettes by breaking them down into component parts. This would be to miss the qualities that intensities produce. In these encounters, the felt sense of each moment-to-moment qualitative transition draws from an immanent background of potential: surprising us, catching us slightly off-guard, demanding our attention. We like the way that Kathleen Stewart's (2015) writing has an uncanny knack of drawing out the singularities of ordinary life, and we hope that the presentation of our supercommuter encounters here might also perform with a similar impressionistic verve.

As our impressionistic presentations suggest, supercommuters attune throughout their travels to "collectively constitute rhythmic choreograph(-ies)" (Edensor 2011, 195) that depend on their skilfulness, alertness, endurance, swiftness, agility, coordination, and knowledge of lay geographies. Floatplane pilots do so when they read the weather and choose routes accordingly, for example. Train commuters do so when delays force them to re-assess their connections. And frequent fliers do so when they assess the situational performance of the aircraft and when they apply the "little tricks" of inhabiting the flight cabin more comfortably. Yet at the same time, as Massumi suggests, the singular qualities of any specific mobility experience means that there will always be intensities that surprise us; intensities that stick out; and intensities that, whilst perhaps not overwhelming our capacities and skills to keep moving, are mildly disorientating enough to remind us of the richness and complexity of any present moment.

\section{Conclusion}

In drawing together the threads from our three impressions, the key dimensions in common amongst these intensively mobile people are related to embodiment, affect, and skill. Learning to cope with-or more broadly learning to expertly practice-supercommuting is a complex affair 
demanding abstract and technical capacities regardless of whether one is piloting or passengering. In particular we have seen how across the three field sites we described the intensities felt by our participants emerge in a complex interplay with knowledge, technologies, embodied sensations, and the travelled environment. The material geographies and landscapes crossed by the trajectories of travel are experienced through the mediated impressions of aircraft and train compartments. In particular, the way in which wind, turbulence, waves, fog, etc. are experienced as intensified sensations seem to stand out as something especially significant to people who travel a lot. As explained, the notion of intensive mobilities is not (just) about quantities: how much, how far, and how fast one travels. To be sure, the quantitative dimensions of kinetic intensity are important. This also goes for quantifying the environmental impacts of increased commuting practices, as well as for the repercussions such intensified practices may have for people's abilities to establish and sustain healthy social relations and networks across time and space. But what we wanted to address with this paper in particular are the many and complex qualitative dimensions emerging out of intense commuter experiences.

The intensities of embodied sensations described across our three impressions suggest that next to an impressive number of abstract and context-independent types of knowledge (e.g. technical flight operation procedures, skills for booking seats and tickets, and everyday life logistics) the supercommuter accumulates a number of bodily capacities to affect and be affected by these systems and infrastructures. Such embodied knowledge speaks indeed to the intensities and the qualitative and experiential dimension of knowledge related to "mobilities in situ" (Jensen 2013). The bodies of knowledge required of supercommuters unfold as minute and often tacit ways of knowing such as knowing when, for example, to push or hold for a particular strategy, or the meaning of particular sounds and kinetic reactions between the machine and the body. Many of such embodied ways of knowing are precisely of the intense nature that defies rationalization and verbalization and can only be felt as a raw form of kinetic energy. Just as intensities are not felt in themselves, these ways of knowing are more connected to the situational assemblages of machines, bodies, rules, regulations, weather, and geographies. The strange familiarity and expertise growing out of routines thus manifest itself as an ambience or sensation that takes years of experience and thousands of travel kilometres to acquire and recognize. Inhabitants of these highly mobile worlds live ordinary lives under extraordinary circumstances and the notion of intensity is just one attempt to engage and explore this often non-articulated and tacit level of kinetic energy and knowledge.

In relation to policies and strategies for changing or re-ordering vastly-increasing commuting practices we see an even further need for exploration. How are long-distance commutes affecting people's everyday life and how are they establishing new paths of dependencies between distant physical geographies? How do disparate regions and separated localities of work and accommodation nest into extensive systems of long-distance commutes? And, further, how do cities, regions, and governments deal with the establishment of infrastructures and systems hosting and accommodating such practices? These are but a few of the political-practical issues that the increasing commuting phenomenon begs answering. It is in relation to such mundane issues that we want to stress that the qualitative, experiential, and embodied sensations of becoming a mobile subject of intense mobilities needs heightened awareness. People work, live, and sense life on the move. Therefore insights into the intensities of mobilities may provide us with a much more finegrained vocabulary for understanding everyday mobilities.

Future research into intensive mobilities, we suggest, should expand our empirical knowledge through more cases within other transportation modes and other geographies. Also, we would be the first to accept that the conceptual framework laid out here is a provisional opening. There are many modes of theorising in mobilities research influenced by new materialist thought and non-representational theory, for instance, that could be drawn on to expand these ideas of intensive mobilities. The future perspective for research into intensities of mobilities requires rethinking the theoretical and conceptual interfaces of these streams of thought as well as that of 
building new empirical knowledge. 


\section{References}

Adey, P., Bissell, D., Hannam, K., Merriman, P. and Sheller, M., 2014. Introduction. The Routledge handbook of mobilities. Routledge.

Bissell, D., 2010. Passenger mobilities: affective atmospheres and the sociality of public transport. Environment and Planning D: Society and Space, 28(2), pp.270-289.

Bissell, D., 2013. Pointless mobilities: rethinking proximity through the loops of neighbourhood. Mobilities, 8(3), pp.349-367.

BITRE, 2012. Australia's commuting distance: cities and regions. Bureau of Infrastructure, Transport and Regional Economics, https://bitre.gov.au/publications/2015/files/is 073.pdf

Brown, K. 2012. "Sharing Public Space across Difference: Attunement and the Contested Burdens of Choreographing Encounter." Social and Cultural Geography 13 (7): 801-820

Burrell, K., 2011. Going steerage on Ryanair: cultures of migrant air travel between Poland and the UK. Journal of Transport Geography, 19(5), pp.1023-1030.

Conradson, D. and McKay, D., 2007. Translocal subjectivities: mobility, connection, emotion. Mobilities, 2(2), pp.167-174.

Cook, M. and T. Edensor. 2014. "Cycling through Dark Space: Apprehending Landscape Otherwise." Mobilities. Published online Nov 212014.

Fincham, B. 2007. "Bicycle Messsengers: Image, Identity and Community." In Cycling and Society, edited by D. Horton, P. Rosen and P. Cox, 179-192. Aldershot: Ashgate.

Edensor, T., 2003. Defamiliarizing the mundane roadscape. Space and Culture, 6(2), pp.151-168.

Edensor, T. 2011. "The Rhythms of Commuting." In Mobilities: Practices, Spaces, Subjects, edited by T. Cresswell and P. Merriman, 189-203. Aldershot: Ashgate.

Goffman, E., 2008. Behavior in public places. New York: Simon and Schuster.

Grosz, E.A., 1994. Volatile bodies: Toward a corporeal feminism. Indiana University Press.

Hardill, I. and Green, A., 2003. Remote working-altering the spatial contours of work and home in the new economy. New Technology, Work and Employment, 18(3), pp.212-222.

Ingold, T. 2000. The Perception of the Environment: Essays on Livelihood, Dwelling and Skill. London: Routledge.

Ingold, T. 2007. Lines. London: Routledge.

Jensen, O.B., 2006. 'Facework', flow and the city: Simmel, Goffman, and mobility in the contemporary city. Mobilities, 1(2), pp.143-165.

Jensen, O. B. (2013) Staging Mobilities, London: Routledge.

Jirón, P., 2010. Mobile borders in urban daily mobility practices in Santiago de Chile. International Political Sociology, 4(1), pp.66-79.

Jones, P. 2012. "Sensory Indiscipline and Affect: A Study of Commuter Cycling." Social and Cultural Geography 13 (6): 645-658.

Jungnickel, K., and R. Aldred. 2014. “Cycling's Sensory Strategies: How Cyclists Mediate Their exposure to the Urban Environment." Mobilities 9 (2): 238-255

Kelly, J.F. and Donegan, P., 2015. City Limits: Why Australia's cities are broken and how we can fix them. Melbourne Univ. Publishing.

Klaeger, G. 2012. "Rush and Relax: The Rhythms and Speeds of Touting Perishable Products on a Ghanian Roadside." Mobilities 7 (4): 537-554.

Lash, S., 2010. Intensive culture: Social theory, religion \& contemporary capitalism. Sage.

Laurier, E. and Lorimer, H., 2012. Other ways: Landscapes of commuting.Landscape Research, 37(2), pp.207224.

Lingis, A. 1998. Foreign Bodies. Bloomington, IN: Indiana University Press.

Mader, M.B., 2014. Whence Intensity? Deleuze and the Revival of a Concept. In Beaulieu, A, Kazarian, E. and Sushytska, J. (eds). Gilles Deleuze and Metaphysics, 225-248.

Massumi, B., 2002. Parables for the virtual: Movement, affect, sensation. Duke University Press.

Massumi, B. 2016. 'Such As It Is: A Short Essay in Extreme Realism', Body \& Society, 22(1), 115-127.

Merleau-Ponty, M. 1968. Phenomenology of Perception. London: Routledge.

Morris, M., 1988. At Henry Parkes Motel. Cultural studies, 2(1), pp.1-47.

Normark, D., 2006. Tending to mobility: intensities of staying at the petrol station. Environment and Planning A, 38(2), pp.241-252.

Pinch, P. and S. Reimer. 2012. "Moto-mobilities: Geographies of the Motorcycle and Motorcyclists." Mobilities 7 (3): 439-457.

Ralph, D. 2014. Work, Family and Commuting in Europe: The Lives of Euro-commuters, London: Palgrave. 
Sandow, E. and Westin, K., 2010. The persevering commuter-Duration of long-distance commuting. Transportation Research Part A: Policy and Practice, 44(6), pp.433-445.

Seigworth, G.J. and Gregg, M., 2010. An inventory of shimmers. The affect theory reader, pp.1-25.

Sheller, M. 2004. "Automotive Emotions: Feeling the Car." Theory, Culture \& Society 21 (4-5): 221-242.

Sheller, M. and Urry, J., 2004. Tourism mobilities: places to play, places in play. Routledge

Sheller, M. and Urry, J., 2006. The new mobilities paradigm. Environment and planning A, 38(2), pp.207-226.

Simmel, G. (1903/1969) 'The metropolis and mental life', in Classic Essays on the Culture of Cities. Ed. Sennett, R. Prentice Hall: Englewood Cliffs, New Jersey

Simont, J. 1999. Intensity, or the encounter. In "Khalfa, J. Introduction to the Philosophy of Gilles Deleuze. Continuum: London. p. 26-49.

Spinney, J. 2006. "A Place of Sense: A Kinaesthetic Ethnography of Cyclists on Mont Ventoux." Environment and Planning D: Society and Space 24: 709-732.

Stewart, K. (2015) New England Red, in P. Vannini (ed.) (2015) Non-Representational Methodologies: Reenvisioning Research, London: Routledge, pp. 19-23.

Thrift, N. (2008) Non-representational theory. Space. Politics. Affect, London: Routledge.

Van Maanen, J. 1984. Tales of the Field: On Writing Ethnography. Chicago: University of Chicago Press.

Vannini, P. (ed.) (2015) Non-representational methodologies: Re-envisioning research, London: Routledge.

Vergunst, J. 2011. "Technology and Technique in a Useful Ethnography of Movement." Mobilities 6 (2): 203219.

Viry, G. and Kaufmann, V. 2015. High Mobility in Europe: Work and Personal Life, London: Palgrave.

Waitt, G., Harada, T. and Duffy, M., 2015. 'Let's Have Some Music': Sound, Gender and Car Mobility. Mobilities, pp.1-19.

Wilson, H.F., 2011. Passing propinquities in the multicultural city: the everyday encounters of bus passengering. Environment and Planning A,43(3), pp.634-649. 